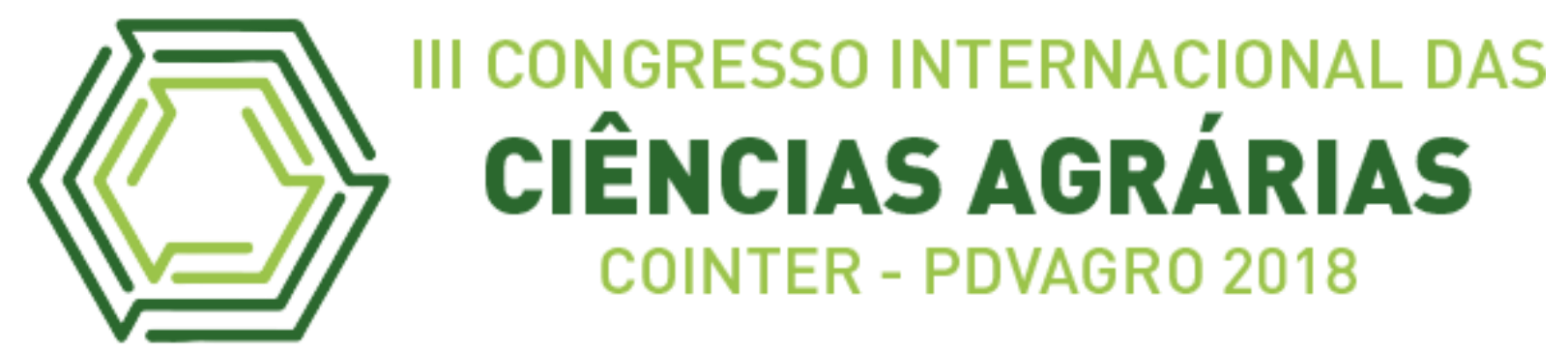

\title{
CARACTERIZAÇÃO DA PRODUÇÃO DE CARNE DE OVINOS E CAPRINOS NO MUNICÍPIO DE IMPERATRIZ
}

\section{CHARACTERIZATION OF THE PRODUCTION OF SHEEP AND GOATMEAT IN THE IMPERATRIO MUNICIPAL}

\author{
Apresentação: Pôster \\ Juciê Leite dos Santos ${ }^{1}$; Samara de Castro Loura ${ }^{2}$; Rayane Leite dos Santos ${ }^{3}$; \\ Isabelle Batista Santos ${ }^{4}$
}

\section{DOI: https://doi.org/10.31692/2526-7701.IIICOINTERPDVAGRO.2018.00360}

\section{Introdução}

A criação de caprinos e ovinos é muito importante para os pequenos produtores, pois esses animais servem como alimento para a subsistência de suas famílias fornecendo carne e leite ou para venda no mercado. A ovinocaprinocultura é uma das atividades pecuárias mais antigas do país, existindo desde período da ocupação portuguesa. Presente em todas as cinco grandes regiões do país, mas com predomínio no Nordeste (SOUZA e CEOLIN, 2013).

Graças aos requisitos que a tornam privilegiada para a exploração de ovinos e caprinos, a cidade de Imperatriz, é a segunda maior produtora no estado do Maranhão. Porém, para que a ovinocultura e a caprinocultura maranhense se transformem em negócios economicamente sustentáveis, gerando excedentes para os subsistemas de produção, processamento e distribuição, faz se necessário adotar programas voltados para adoção de tecnologias economicamente viáveis, com vista à superação dos entraves ao desenvolvimento dessas cadeias produtivas (SEBRAE/MA, 2009).

Assim, objetivou-se com esse estudo, analisar o perfil do produtor e a produção de caprinos e ovinos na região de Imperatriz-MA, destacando seu principal sistema de criação, suas formas de manejo alimentar e reprodutivo.

\footnotetext{
${ }^{1}$ Curso, Instituição, E-mail Medicina veterinária, UEMASUL, jucieleite@hotmail.com

${ }^{2}$ Curso, Instituição E-mail Medicina Veterinária, UEMASUL, saamaaraa.s2@hotmail.com

${ }^{3}$ Curso, Instituição, E-mail Tecnologia de alimentos, IFMA, rayannyleite@hotmail.com

${ }^{4}$ Titulação, Instituição, e-mail Mestre, UEMASUL,isabellebatista@yahoo.com.br
} 


\section{Fundamentação Teórica}

Segundo Martins et al. (2015), em 2013 a produção mundial de carne caprina e ovina alcançou 5,4 e 8,6 milhões de toneladas, respectivamente. No mercado de carnes no Brasil, o consumo de carne ovina é considerado muito baixo. O consumo anual per capita de carne ovina no país é em torno de 700 gramas, contra um consumo anual per capita de $39 \mathrm{~kg}$ de carne bovina, 44,5 kg carne de frango e $13 \mathrm{~kg}$ carne suína (ANUALPEC, 2011).

Os consumidores consideram a carne ovina como exótica apropriada para festividades ou ocasiões especiais, e a alta gastronomia já descobriu essa iguaria. Como há poucos produtores nacionais que conseguem atender, de forma regular, o mercado de restaurantes, grande parcela dessa crescente demanda é atendida por distribuidores que importam carne (ROCHA et al., 2010).

Isso ocorre principalmente porque nos estados produtores, como o Maranhão por exemplo, a caprinocultura e a ovinocultura revelam-se como atividades de consideráveis perspectivas, porém, a desarticulação da cadeia produtiva não tem proporcionado uma condição de velocidade no desenvolvimento destas atividades na região (SILVA, 2011).

\section{Metodologia}

A presente pesquisa classifica-se como quali-quantitativa, pois enfatiza o levantamento de informações sobre as características da produção, bem como a demanda do mercado para a criação de ovinos e caprinos. A pesquisa foi realizada no município de Imperatriz - MA. A cidade localiza-se no oeste do estado do Maranhão a 629,5 km da capital. A priori, foram feitas pesquisas nas propriedades produtoras de caprinos e ovinos na cidade e algumas informações foram obtidas através da Agencia de defesa sanitária do estado a AGED. Para a execução deste estudo foram aplicados questionários semiestruturados contendo 18 perguntas abordando questões socioeconômicas (gênero, idade, grau de escolaridade e renda mensal familiar) e os aspectos relacionados a indicadores da propriedade, atividades de pecuária, manejo alimentar e reprodutivo manejo sanitário, rentabilidade e exploração. A pesquisa foi realizada em 20 propriedades, onde a aplicação do questionário foi feito no período de 07 de julho de 2017 a 20 de março de 2018. 


\section{Resultados e Discussões}

O quadro 1, apresenta os principais dados obtidos através das entrevistas com os produtores.

Quadro 01: Principais características dos produtores e das propriedades de ovinos e caprinos

\begin{tabular}{|c|c|c|c|c|c|c|}
\hline DESCRIÇÃO & $\begin{array}{l}\text { Produtor } \\
\text { Idade/escolaridad } \\
\text { e }\end{array}$ & $\begin{array}{l}\text { Tamanho } \\
\text { da } \\
\text { Proprieda } \\
\text { de (ha) }\end{array}$ & $\begin{array}{l}\text { Rebanho } \\
\text { (ovino / } \\
\text { caprino) }\end{array}$ & $\begin{array}{l}\text { Tipo Racial } \\
\text { predominante } \\
\text { (Ovino/caprin } \\
\text { o) }\end{array}$ & Outras atividades & $\begin{array}{l}\text { Principal fonte } \\
\text { de volumoso }\end{array}$ \\
\hline Propriedade 01 & $\begin{array}{l}68 \text { anos /Ens. Fun. } \\
\text { Incompleto }\end{array}$ & 40 & 45 Ovinos & Mestiço & $\begin{array}{l}\text { Bovinocultura } \\
\text { Equideocultura } \\
\text { Roça }\end{array}$ & $\begin{array}{l}\text { Pastagens } \\
\text { cultivadas }\end{array}$ \\
\hline Propriedade 02 & $\begin{array}{l}63 \text { anos/ Ens. } \\
\text { Fund. Completo }\end{array}$ & 60 & 50 Ovinos & Mestiço & Bovinocultura Roça & $\begin{array}{l}\text { Pastagens } \\
\text { cultivadas } \\
\text { nativas }\end{array}$ \\
\hline Propriedade 03 & $\begin{array}{l}48 \text { anos / Ens. } \\
\text { Méd. Completo }\end{array}$ & 130 ha & $\begin{array}{l}15 \text { Ovinos } \\
\text { 23Caprinos }\end{array}$ & Santa Inês & $\begin{array}{l}\text { Equideocultura } \\
\text { Bovinocultura } \\
\text { Avicultura }\end{array}$ & $\begin{array}{l}\text { Pastagens } \\
\text { cultivadas } \\
\text { nativas }\end{array}$ \\
\hline Propriedade 04 & $\begin{array}{l}67 \text { anos / Ens. Sup. } \\
\text { Completo }\end{array}$ & 130 ha & 24 Ovinos & Santa Inês & $\begin{array}{l}\text { Equideocultura } \\
\text { Bovinocultura } \\
\text { Avicultura }\end{array}$ & $\begin{array}{l}\text { Pastagens } \\
\text { cultivadas } \\
\text { nativas }\end{array}$ \\
\hline Propriedade 05 & $\begin{array}{l}54 \text { anos / Ens. Sup. } \\
\text { Incompleto }\end{array}$ & 38 & $\begin{array}{l}99 \text { Ovinos } 2 \\
\text { Caprinos }\end{array}$ & $\begin{array}{ll}\text { Santa Inês } & \text { e } \\
\text { Dorper } & \text { e } \\
\text { Mestiço } & \end{array}$ & $\begin{array}{l}\text { Equeodicultura } \\
\text { Bovinocultura } \\
\text { Suinocultura }\end{array}$ & $\begin{array}{l}\text { Pastagens } \\
\text { cultivadas } \\
\text { nativas }\end{array}$ \\
\hline Propriedade 06 & $\begin{array}{l}67 \text { anos / Ensi. Sup. } \\
\text { Completo }\end{array}$ & 36 & 44 Ovinos & Santa Inês & $\begin{array}{l}\text { Equeodicultura } \\
\text { Bovinocultura }\end{array}$ & $\begin{array}{l}\text { Pastagens } \\
\text { cultivadas } \\
\text { nativas }\end{array}$ \\
\hline Propriedade 07 & $\begin{array}{l}60 \text { anos / Ens. Fun. } \\
\text { Incompleto }\end{array}$ & 30 & $\begin{array}{l}60 \text { Ovinos } \\
\text { 17Caprinos }\end{array}$ & $\begin{array}{l}\text { Mestiço e } \\
\text { Santa Inês }\end{array}$ & $\begin{array}{l}\text { Equeodicultura } \\
\text { Suinocultura }\end{array}$ & $\begin{array}{l}\text { Pastagens } \\
\text { cultivadas e } \\
\text { nativas }\end{array}$ \\
\hline Propriedade 08 & $\begin{array}{l}62 \text { anos/Ens.Fun. } \\
\text { Completo }\end{array}$ & $5.600 \mathrm{~m}$ & $\begin{array}{l}22 \text { ovinos } \\
2 \text { caprinos }\end{array}$ & $\begin{array}{l}\text { Santa Inês } \\
\text { Mestiço- } \\
\text { caprinos }\end{array}$ & $\begin{array}{l}\text { Bovinocultura } \\
\text { Equideocultura } \\
\text { avicultura }\end{array}$ & $\begin{array}{l}\text { Pastagens } \\
\text { cultivadas } \\
\text { nativas }\end{array}$ \\
\hline Propriedade 09 & $\begin{array}{l}60 \text { anos/ Ens. Méd. } \\
\text { completo }\end{array}$ & 120 & 55 Ovinos & Santa Inês & $\begin{array}{l}\text { Bovinocultura } \\
\text { Suinocultura } \\
\text { Avicultura }\end{array}$ & $\begin{array}{l}\text { Pastagem } \\
\text { cultivadas } \\
\text { nativas }\end{array}$ \\
\hline $\begin{array}{l}\text { Propriedade } \\
10\end{array}$ & $\begin{array}{l}55 \text { anos/ Ens. Fun. } \\
\text { Incompleto }\end{array}$ & 70 & 70 caprinos & Mestiço & $\begin{array}{l}\text { Bovinocultura } \\
\text { Equideocultura }\end{array}$ & $\begin{array}{l}\text { Pastagens } \\
\text { cultivadas } \\
\text { nativas }\end{array}$ \\
\hline Propriedade 11 & $\begin{array}{l}39 \text { anos/ Ens. Sup. } \\
\text { Completo }\end{array}$ & 300 & 56 Ovinos & Santa Inês & $\begin{array}{l}\text { Bovinocultura } \\
\text { Equideocultura }\end{array}$ & $\begin{array}{l}\text { Pastagens } \\
\text { cultivadas e } \\
\text { nativas }\end{array}$ \\
\hline
\end{tabular}




\begin{tabular}{|c|c|c|c|c|c|c|}
\hline Propriedade 12 & $\begin{array}{l}63 \text { anos/ Ens. Méd. } \\
\text { Completo }\end{array}$ & 300 & $\begin{array}{l}40 \text { Ovinos } \\
70 \text { Caprinos }\end{array}$ & $\begin{array}{l}\text { Santa Inês } \\
\text { Mestiço- } \\
\text { caprinos }\end{array}$ & $\begin{array}{l}\text { Bovinocultura } \\
\text { Equideocultura }\end{array}$ & $\begin{array}{l}\text { Pastagens } \\
\text { cultivadas } \\
\text { nativas }\end{array}$ \\
\hline Propriedade 13 & $\begin{array}{l}67 \text { anos/ Ens. Méd. } \\
\text { Completo }\end{array}$ & 104 & 25 Ovinos & Santa Inês & $\begin{array}{l}\text { Bovinocultura } \\
\text { Equideocultura }\end{array}$ & $\begin{array}{l}\text { Pastagens } \\
\text { cultivadas e } \\
\text { nativas }\end{array}$ \\
\hline Propriedade 14 & $\begin{array}{l}43 \text { anos/ Ens. Méd. } \\
\text { Completo }\end{array}$ & 60 & $\begin{array}{l}31 \text { Ovinos } \\
\text { 60Caprinos }\end{array}$ & Mestiço & Avicultura & $\begin{array}{l}\text { Pastagens } \\
\text { cultivadas e } \\
\text { nativas }\end{array}$ \\
\hline Propriedade 15 & $\begin{array}{l}40 \text { anos/ Ens. Méd. } \\
\text { Completo }\end{array}$ & 15 & 31 Ovinos & Mestiço & $\begin{array}{l}\text { Bovinocultura } \\
\text { Avecultura }\end{array}$ & $\begin{array}{l}\text { Pastagens } \\
\text { cultivadas e } \\
\text { nativas }\end{array}$ \\
\hline Propriedade 16 & $\begin{array}{l}53 \text { anos/ Ens. Fun. } \\
\text { Completo }\end{array}$ & 28 & 12 Ovinos & Mestiço & $\begin{array}{l}\text { Bovinocultura } \\
\text { Avicultura }\end{array}$ & $\begin{array}{l}\text { Pastagens } \\
\text { cultivadas }\end{array}$ \\
\hline Propriedade 17 & $\begin{array}{l}62 \text { anos/ Ens. Fun. } \\
\text { Incompleto }\end{array}$ & 55 & 31 Ovinos & Mestiços & $\begin{array}{l}\text { Bovinocultura } \\
\text { Avicultura }\end{array}$ & $\begin{array}{l}\text { Pastagens } \\
\text { cultivadas } \\
\text { nativas }\end{array}$ \\
\hline Propriedade 18 & $\begin{array}{l}51 \text { anos/ Ens. Méd. } \\
\text { Completo }\end{array}$ & 37 & 11 Ovinos & $\begin{array}{l}\text { Santa Inês e } \\
\text { Mestiço }\end{array}$ & $\begin{array}{l}\text { Bovinocultura } \\
\text { Avicultura }\end{array}$ & $\begin{array}{l}\text { Pastagens } \\
\text { cultivadas e } \\
\text { nativas }\end{array}$ \\
\hline Propriedade 19 & $\begin{array}{l}47 \text { anos/ Ens. Fun. } \\
\text { Completo }\end{array}$ & 12 & 11 Ovinos & $\begin{array}{l}\text { Santa Inês e } \\
\text { Mestiço }\end{array}$ & $\begin{array}{l}\text { Bovinocultura } \\
\text { Avicultura }\end{array}$ & $\begin{array}{l}\text { Pastagens } \\
\text { cultivadas } \\
\text { nativas }\end{array}$ \\
\hline Propriedade 20 & $\begin{array}{l}38 \text { anos/ Ens. Fun. } \\
\text { Completo }\end{array}$ & 19 & 23 Ovinos & $\begin{array}{l}\text { Santa Inês e } \\
\text { Mestiço }\end{array}$ & $\begin{array}{l}\text { Bovinocultura } \\
\text { Avicultura } \\
\text { Equideocultura }\end{array}$ & $\begin{array}{l}\text { Pastagens } \\
\text { cultivadas }\end{array}$ \\
\hline
\end{tabular}

A idade média dos produtores de caprinos e ovinos é de 52 anos. Esses resultados diferem dos encontrados nas pesquisas de Cardoso et al. (2015), onde as idades dos proprietários estudados variavam de 19 a 86 anos de idade. Esta variação de idade pode estar relacionada a cultura da região. Enquanto no Nordeste a maioria dos jovens não possui interesse em atividades agropecuárias e permanecer muito tempo no campo, enquanto na região Sudeste não há muito essa resistência dos jovens em investir em trabalhos no meio rural.

A escolaridade de grande parte (35\%) dos produtores foi o ensino médio completo, semelhante aos resultados encontrados por Silva (2014), onde a escolaridade da maioria produtores foi o ensino médio e superior. Apesar de um número razoável de produtores possuírem nível superior, uma grande parcela de produtores ainda possui baixa escolaridade. Ter conhecimento sobre o perfil dos produtores em relação à escolaridade é muito importante 
para que assim seja possível a criação de políticas de capacitação específicas, destinadas a melhor exploração da atividade.

Verificou-se em todas as propriedades um sistema de produção associativo; com caprinos, ovinos elou outra criação e atividade de roça. Essa diversificação de atividades é bastante comum nas pequenas e médias propriedades rurais, visando melhor exploração dos recursos da propriedade e diversificação das fontes de renda. Quanto à diversificação das raças dos animais está de acordo com o esperado, visto que segundo os estudos de Silva (2011) sobre ovinocultura e caprinocultura no estado do Maranhão é bastante comum encontrar nas propriedades as raças Santa Inês, sem padrão racial (mestiços), Dorper e outros.

Os dados quanto à alimentação estão de acordo com a pesquisa de Silva (2011), manejo alimentar dispensado aos ovinos e caprinos predominantes à utilização da pastagem natural o ano todo. Esse sistema de manejo alimentar pode suportar a produção pecuária em razão do regime de chuvas na maior parte do estado do Maranhão. A utilização de alimentação especial é utilizada apenas por alguns produtores que, em muitos casos, realizam a técnica da conservação de forragens, com predomínio para a silagem, utilizando-se, principalmente, do Capim Mombaça e Brachiaria na sua confecção. Com relação à mineralização, a maioria (70\%) dos produtores adota esse procedimento. Dada a importância dessa prática para as funções vitais dos animais, o ideal seria que todos os produtores a praticassem. Esse resultado difere do encontrado por Silva (2011) para o estado do Maranhão.

Os resultados revelaram que a maioria $(75 \%)$ dos proprietários do presente estudo castram seus animais, seja por método cirúrgico (50\%) ou por faca mesmo (25\%). Este resultado difere do encontrado por Quinzeiro Neto (2007), em que nos dados sobre o manejo dos machos, observou-se que maioria dos produtores $(91,3 \%)$ não castrava seus animais. Essa prática é importante, pois permite a obtenção de carcaças melhores aceitas para o consumo.

Quanto ao manejo reprodutivo a monta natural não controlada é pratica quase unânime nas propriedades estudadas, sendo que apenas em uma propriedade é realizada a monta natural controlada. Segundo a pesquisa de Silva (2011) por ser o método mais simples, a monta natural é amplamente utilizada no Nordeste, pois o uso do sistema extensivo favorece essa prática.

Quanto à comercialização da carne de ovinos nas propriedades estudadas o comercio diferiu entre as propriedades, no que se refere aos compradores, se direto ao consumidor final ou para intermediários/feirantes. 


\section{Conclusões}

Inquestionavelmente, os principais problemas enfrentados pela ovinocaprinocultura de Imperatriz, Maranhão estão relacionadas a questões tecnológicas, principalmente na escolha da raça adequada, do manejo empregado na prática reprodutiva, quanto à monta, seleção, observações de cio, sanidade e no manejo alimentar. Esses dados apontam a necessidade de desenvolver projetos que levem conhecimento aos criadores do município de Imperatriz- Ma sobre as formas corretas de manejo reprodutivo, sanidade, manejo alimentar e a importância da escolha da raça desses animais, para que dessa forma a cadeia produtiva de ovinos e caprinos no município possa se desenvolver e ganhar a valorização do mercado.

\section{Referências}

CARDOSO, M.V. et al., Caracterização da caprinocultura e ovinocultura no estado de São Paulo. Arq. Inst. Biol., São Paulo, v.82, p. 1-15, 2015.

MARTINS, E. C. et al., Panorama e perspectiva mundial da ovinocultura e caprinocultura. $2015 . \quad$ Disponível em: https://www.embrapa.br/documents/1355090/0/Panorama+Mundial+Caprinocultura+e+Ovino cultura/d15ea59a-d9d1-4436-9f82-b84870d766ef?version=1.0. Acesso em: 21 jan. 2017.

QUINZEIRO NETO, Talmir. Caracterização dos sistemas de produção de carne caprina e ovina dos produtores associados às cooperativas de Jussara e Valente - BA. 2007. 52f. Dissertação (mestrado em zootecnia) - Escola de Veterinária da Universidade Federal de Minas Gerais, Belo Horizonte. Disponível em: https://vet.ufmg.br/DOWNLOAD.php?o=8\&i=20140602141318\&a=caracterizacao_dos_ sistemas_de_producao_de_carne_caprina_e_ovina_dos_. Acesso em 10 abr. 2018.

SERVIÇO DE APOIO ÀS MICRO E PEQUENAS EMPRESAS - SEBRAE/MA. Ovinocaprinocultura: Diagnóstico. São Luís, 2009. Disponível em: < http://www.sebrae.com.br/uf/maranhao/integra_documento?documento=5D1E5C3BC8 A3E377832575D600622A3F >. Acessa em: 18 jan. 2017.

SILVA, L. F. do N. Perfil de produtores da associação de criadores de cabras leiteiras do Leste e Agreste Potiguar, 60f. Dissertação - (Mestrado em Zootecnia). UFRN, Macaíba-RN, 2014.

SILVA, J. V. Caracterização dos sistemas de produção de ovinos e caprinos no estado do maranhão. Areia-PA, 2011. Disponível em: http://www.cca.ufpb.br/ppgz/www/files/teses2011/TESE_Caracterizao_dos_Sistemas_de_Pr 
oduo_de_Ovinos_e_Caprinos_no_Estado_do_Maranho_Josiane_Veloso_da_Silva.pdf. Acesso em: 25 jan. 2017. 